\title{
Measurement and Analysis of China's Provincial Carbon Finance Level
}

\author{
Quanjia Zuo* \\ School of Practical Economics, Nanjing University of Science \& Technology, Nanjing, Jiangsu 210094, China. \\ *Corresponding author. Email:1909671098@qq.com
}

\begin{abstract}
With China's comprehensive deepening of reforms and improvement of the financial market, carbon finance has played an increasingly important role in supporting and driving green industries. A comparative analysis of the development of provincial carbon finance in China can provide theoretical support for national research related policies. This paper uses the principal component analysis method to innovatively construct a provincial carbon finance development index evaluation system. Through comparative analysis, it is found that those with higher levels of carbon finance development are provinces with higher economic and technological levels, while those with lower levels are resource-intensive provinces. It is recommended that governments at all levels vigorously develop low-carbon technologies and increase fiscal expenditures on energy conservation and environmental protection.
\end{abstract}

Keywords: Carbon finance, principal component analysis, index evaluation

\section{INTRODUCTION}

At present, China has begun to recognize the shortcomings of the economic structure and development methods, and has begun to supply-side structural reforms, the development level of carbon finance has become an important factor affecting supply-side structural reforms [1]. The so-called carbon finance refers to the relevant systems and policy arrangements of the financial industry that serve carbon emission reduction and the development of energy conservation and environmental protection industries [2]. China's carbon finance development level is relatively lagging. Since 1960 , the cumulative global carbon emissions have been $12,438.63$ billion tons, of which 190.4 billion tons were emitted by China, accounting for about $15.3 \%$ (www.tanpaifang.com). As a leading developing country and the world's second largest economy, China's contribution to carbon reduction is in urgent need of further increase.

In recent years, with China's comprehensive deepening of reforms and improvement of the financial market, the financial industry's support for the energy-saving and environmental protection industry has attracted more and more attention, and carbon finance's support and driving role for the green industry has also increased. Since the "Kyoto Protocol" came into effect in 2005, China, as a developing country, has no hard requirements to reduce greenhouse gas emissions by 2012. At the same time, China can participate in clean development mechanism (CDM) project development, and can convert the reduced greenhouse gas emissions into certified emission reduction units according to the CDM mechanism and sell them to developed countries. As of 2013, China has been a major supplier in the CDM market, with a market share of around $70 \%$ (IEA, 2014). It can be seen from this that China's carbon financial market has broad development prospects.

Therefore, it is particularly important and urgent to make an exponential evaluation of the development of China's provincial carbon finance, and to make a comparative analysis based on the situation of each province. At the national level, it can provide theoretical support for national research-related policies, and through regional research, we can draw conclusions and recommendations that are suitable for the whole country. At the regional level, it can help provinces recognize the development level of the province's carbon finance and the differences with other provinces, and can help provinces recognize their own shortcomings and improve the level of carbon finance development in a targeted manner [3].

This paper uses the principal component analysis method to innovatively construct an index evaluation system for China's provincial carbon finance development level, evaluates and ranks the carbon finance development level of each province in China, and combines with the actual situation of each province to analysis the impact of carbon finance development. Factors of the level, put forward policies and recommendations.

The remainder of this paper is structured as follows. First, a systematic review of the literature is conducted in Section 2. Section 3 builds an index evaluation system for carbon finance development level of provinces. Conclusions are given in Section 4. 


\section{LITERATURE REVIEW}

\subsection{China's Carbon Finance Development Status}

As the world's second-largest economy and largest developing country, China faces huge challenges in terms of a low-carbon economy. In the 13th Five-Year Plan, the Chinese government has ranked carbon reduction as an important goal of economic development. In order to play an important role of the financial industry in carbon emission reduction, China has successively established carbon trading pilots and a nationwide carbon trading market [4].

At present, the most developed market for carbon finance is the European market. However, China's carbon trading market has broader development prospects. It is estimated that by 2030, China's carbon emission reductions can reach 2-30 billion tons, exceeding the EU's emission reductions [5]. The development of the carbon financial market is not only a requirement of the Chinese government for local governments, in fact, the carbon market can fundamentally promote the process of talking about emission reductions [6]. Therefore, China is striving to develop a carbon trading market and play a role in promoting the carbon emission reduction of the carbon market [7].

\subsection{Influencing Factors of Carbon Finance}

There are many literatures that study the influencing factors of carbon finance development level. Malik A S. pointed out that the industry background has an important impact on the development trend of carbon finance [8]; Jotzo F. and Michaelowa A. believed that market construction is the foundation for the development of carbon finance and only by building and continuously improving the market can carbon finance be developed [9]; Xie C. et, al. proposed that business capacity is also one of the factors that significantly affect the development of carbon finance, i.e. the development level of the carbon emissions trading market will have an impact on the development level of carbon finance [10].

For the research on the influencing factors of China's provincial carbon finance, the research involved is relatively limited. ChuanjiangLiu pointed out that industrial structure adjustment, changes in energy intensity, technological innovation capabilities, clean energy technology level and policy incentives are important factors that affect the development level of regional carbon finance [11]; ShiyiChen et,al. believe that energy technology level and economic development status It is the main factor affecting the development level of regional carbon finance [12]. Through a comparative study of Beijing, Tianjin, Hebei, the Yangtze River Delta, and the Pearl River Delta, LiLi and BijunDong pointed out that, the four factors of automobile exhaust emissions, the number of domestic enterprises above designated size, the development level of the service industry, and the financial support for industrial governance have a significant impact on the development level of carbon finance [13].

\section{CALCULATION OF CARBON FINANCE}

\subsection{Indicator and Data}

With reference to the research of LiLi and BijunDong, based on the availability, rationality and integrity of the data, this paper selects the number of CDM approved projects, the incremental intensity of carbon emission financing, the number of patent authorizations, the average salary of employees in the financial industry, water conservancy environment and public, the average salary of employees in the facility management industry to measure the development level of provincial carbon finance. Data from 30 provinces and cities except for workers in Tibet, Hong Kong, Macau and Taiwan in 2016 were selected for research.

Where, the number of CDM approved projects $\left(\mathrm{X}_{1}\right), \mathrm{CDM}$ is the clean development mechanism; the incremental intensity of carbon emission financing $\left(\mathrm{X}_{2}\right)$ refers to the added value of carbon dioxide emissions caused by each additional unit financing scale; the number of patent authorizations $\left(\mathrm{X}_{3}\right)$ represents The development level of regional science and technology; the average wage of employees in the financial industry $\left(\mathrm{X}_{4}\right)$ represents the development level of the financial industry in a region; the average wage of employees in the water conservancy, environment and public facilities management industry $\left(\mathrm{X}_{5}\right)$ represents the strength level of a regional energy conservation and environmental protection industry.

The number of CDM approved projects comes from the clean development mechanism project database. The incremental strength of financing scale comes from the official website of the People's Bank of China, the carbon dioxide emissions come from "CEADs", and other data come from China Statistical Yearbook.

\subsection{Calculation of Carbon Finance}

\subsubsection{Data processing}

The units of the five indicators are different, and the data are not comparable, so it is necessary to standardize the data. The processing method of this paper is: 


$$
X=\frac{X_{0}-X_{\min }}{X_{\max }-X_{\min }}
$$

Where, $X$ represents the data after processing, $X_{0}$ is the original data, $X_{\min }$ represents the minimum value of the data, $X_{\max }$ is the maximum value of the data.

It is also because $\mathrm{X}_{1}, \mathrm{X}_{3}, \mathrm{X}_{4}$ and $\mathrm{X}_{5}$ are positively correlated with the level of carbon finance development, while $\mathrm{X}_{2}$ is negative related, so it is necessary to differentiate the data of the two cases. In this paper, the data of the first four are expressed as positive values, and the data of the latter are expressed as negative values.

\subsubsection{Calculation}

This paper wants to establish an index evaluation system of the provincial carbon finance development level. Since there are 5 evaluation indicators, the more intuitive method is to give the 5 indicators appropriate weights, and then calculate the weighted sum of the 5 indicators as the final score. However, in actual operation, the weight of each indicator is difficult to obtain, so consider using the principal component analysis method to simplify a number of comprehensive factors from the 5 indicators, called principal components, and assign weights to these principal components, and finally achieve purpose. The results of component extraction are shown in Table 1:
In Table 1 , the cumulative variance contribution rate of component 1 , component 2 and component 3 is $84.431 \%$, which is greater than $80 \%$. Therefore, component 1 , component 2 and component 3 can be used as the main components to perform the main component analysis. The principal component here is not a special indicator in the indicator layer, but three comprehensive indicators resulting from the transformation of the initial five indicators after dimensionality reduction. Each principal component can reflect a large amount of information of the initial index layer, and there is no multicollinearity among the principal components. The cumulative variance contribution rate of each principal component is its weight. For principal components 1,2 and 3, their weights among the three are: $\mathrm{W}_{1}=50.507 \% / 84.431 \%=0.60 ; \mathrm{W}_{2}=$ $18.847 \% / 84.431 \%=0.22 ; \mathrm{W}_{3}=15.076 \% / 84.431 \%=$ 0.18 .

\subsection{Ranking}

The initial value of the principal component can be directly output through the SPSS software, which is expressed as FAC1_1, FAC2_1 and FAC3_1 respectively. The carbon finance development index can be expressed as: $\mathrm{S}=\mathrm{W}_{1} *$ FAC1_1 $+\mathrm{W}_{2} *$ FAC2_1 $+\mathrm{W}_{3} *$ FAC3_1. The final rankings of the provinces are shown in Table 2 below:

Table 1 Variance contribution rate

\begin{tabular}{|c|c|c|c|c|c|c|c|c|c|}
\hline \multicolumn{10}{|c|}{ Explained total variance } \\
\hline \multirow[b]{2}{*}{ Ingredients } & \multicolumn{3}{|c|}{ Initial eigenvalue } & \multicolumn{3}{|c|}{ Extract square sum load } & \multicolumn{3}{|c|}{ Rotate square sum loading } \\
\hline & total & $\begin{array}{c}\text { Variance } \\
\text { percentage }\end{array}$ & $\begin{array}{l}\text { Cumulative } \\
\text { percentage }\end{array}$ & total & $\begin{array}{l}\text { Variance } \\
\text { percentage }\end{array}$ & $\begin{array}{l}\text { Cumulative } \\
\text { percentage }\end{array}$ & total & $\begin{array}{l}\text { Variance } \\
\text { percentage }\end{array}$ & $\begin{array}{l}\text { Cumulative } \\
\text { percentage }\end{array}$ \\
\hline 1 & 2.52 & 50.51 & 50.51 & 2.53 & 50.51 & 50.51 & 1.71 & 34.10 & 34.10 \\
\hline 2 & 0.94 & 18.85 & 69.36 & 0.94 & 18.85 & 69.36 & 1.45 & 29.05 & 63.15 \\
\hline 3 & 0.75 & 15.08 & 84.43 & 0.75 & 15.08 & 84.43 & 1.06 & 21.27 & 84.43 \\
\hline 4 & 0.58 & 11.66 & 96.09 & & & & & & \\
\hline 5 & 0.19 & 3.91 & 100 & & & & & & \\
\hline
\end{tabular}

Table 2 Carbon finance development level ranking

\begin{tabular}{ccccccccc}
\hline $\mathbf{1}$ & $\mathbf{2}$ & $\mathbf{3}$ & $\mathbf{4}$ & $\mathbf{5}$ & $\mathbf{6}$ & $\mathbf{7}$ & $\mathbf{8}$ & $\mathbf{9}$ \\
\hline Guangdong & Jiangsu & Zhejiang & Beijing & Shandong & Sichuan & Gansu & Tianjin & Fujian \\
$\mathbf{1 0}$ & $\mathbf{1 1}$ & $\mathbf{1 2}$ & $\mathbf{1 3}$ & $\mathbf{1 4}$ & $\mathbf{1 5}$ & $\mathbf{1 6}$ & $\mathbf{1 7}$ & $\mathbf{1 8}$ \\
\hline Shanghai & Yunnan & InnerMongolia & Chongqing & Hebei & Shaanxi & Henan & Anhui & Jiangxi \\
$\mathbf{1 9}$ & $\mathbf{2 0}$ & $\mathbf{2 1}$ & $\mathbf{2 2}$ & $\mathbf{2 3}$ & $\mathbf{2 4}$ & $\mathbf{2 5}$ & $\mathbf{2 6}$ & $\mathbf{2 7}$ \\
\hline Hunan & Hubei & Liaoning & Guizhou & Guangxi & Jilin & Guangxi & Jilin & Xinjiang \\
\hline
\end{tabular}




\section{CONCLUSION}

It can be seen that the provinces with better development are mostly coastal provinces. Even if they are not coastal provinces, the level of economic development is also at the forefront of the country. What they have in common is that they are not resource-intensive provinces, the climatic conditions are not bad, the economic level is high, and the level of science and technology is also high. Most of them are on the third ladder.

On the contrary, most of the areas with low carbon finance development are on the first and second steps. It can be roughly divided into three situations. One is the province with bad weather, inconvenient transportation, and low level of economic development, such as the three ethnic minority areas except Inner Mongolia and Tibet, and Guizhou Province and Qinghai Province. These provinces are relatively remote, with low economic levels and bad weather conditions. This has led to their low technical level, the government 's support for carbon finance is small, and the development of the financial industry itself in these places is relatively weak. The second is resourceintensive provinces. The most typical one is Shanxi Province. As a coal base in China, its economic development level is not low, but its carbon finance development level ranks in the bottom one. The main reason is its high level of carbon emissions. Another situation is the heavy industry development bases, such as the three provinces in the east and Hebei provinces. These provinces are traditional heavy industry development bases. They have a high economic level but serious pollution, so the carbon finance development level is not high.

Therefore, the government should vigorously develop lowcarbon technologies and increase fiscal expenditures on energy conservation and environmental protection.

This paper builds a provincial carbon finance evaluation system to provide academic support for the development of the carbon market. But there is no significant research on the influencing factors, which requires further research.

\section{ACKNOWLEDGMENT}

This work was supported by the National Natural Science Foundation of China (Nos. 71704080, 71774087, 71403131), the Fundamental Research Funds for the Central Universities (No. 30917013101), and Jiangsu Province Graduate Research and Practice Innovation Plan(KYCX19_0210).

\section{REFERENCES}

[1] JuanWang,SiyaoWang, Research on Financial Influencing Factors of Supply-side Structural Reform. Beijing Financial Review, (03) (2017) 34-42.

[2] Li, K., Liu, C.,Construction of Carbon Finance System and Promotion of Environmental Finance Innovation in China. Energy Procedia, 5(14) (2011) 1065-1072.

[3] WenjingZhang,HengzhouXu, Effects of land urbanization and land finance on carbon emissions: A panel data analysis for Chinese provinces. Land Use Policy, (04) (2017) 493-500.

[4] Liobikiene, G., Butkus, M., The European Union possibilities to achieve targets of Europe 2020 and Paris agreement climate policy. Renew. Energy, (106) (2017) 298-309.

[5] Zhang, Z., Making the transition to a low-carbon economy: the key challenges for China. Asia \&.Pac. Pol. Stud. 3(2) (2016b) 187-202.

[6] Zhang, Y., Peng, Y., Ma, C., Shen, B., Can environmental innovation facilitate carbon emissions reduction? Evidence from China. Energy Pol. (100) (2017) 18-28.

[7] Kaile Zhou, Yiwen Li, Carbon finance and carbon market in China: Progress and challenges. Journal of Cleaner Production, 2019 536-549.

[8] Malik A S. Enforcement costs and the choice of policy instruments for controlling pollution [J]. Economic Inquiry, 30(4) (1992) 714-721.

[9]Jotzo F, Michaelowa A . Estimating the CDM market under the marrakech accords . Climate Policy[J], (2-3) (2002) 179-196.

[10] Xie C, Xin X, Hou W. Comprehensive Evaluation of Urban Low-Carbon Economy Based on Fuzzy Rough Set,E-Product E-Service and E-Entertainment (ICEEE), 2010 International Conference on. IEEE, $20101-4$.

[11] ChuanjiangLiu, Restrictive factors of low-carbon economic development and the choice of China's lowcarbon road, Journal of Social Science of Jilin University, (3) (2010) 146-152.

[12] ShiyiChen, Energy consumption, carbon dioxide emissions and the sustainable development of Chinese industry, Economic Research, (4) (2009) 41-55.

[13] Li Li, Bijun Dong, Research on the Development Level and Influencing Factors of Regional Carbon Finance, Economics and Management, (01) (2018) 0060-06. 